control is possible with sub-irrigation, the nutrient solution being delivered at the optimum growing temperature. In the actual experimental beds used, the only control effected was to avoid temperatures below freezing-point by building the beds above the ground level. In these latitudes the subsoil may remain frozen when air temperatures are constantly above $0^{\circ} \mathrm{C}$.

As examples of crop yield, the following data may be quoted:

Radish sown 2 July, mature crop harvested 3 August; average yield per bed $=650$ bundles of 12 .

Lettuce sown 3 July, cut 16 August. There is little doubt that with earlier sowing, two successive crops could be matured.

Spinach-performance similar to lettuce.

Cabbage sown 21 June, "transplanted into bed early in August; made rapid growth, but produced only small heads. Could be easily matured if seedlings were raised under glass.

Potatoes set 3 July, grew until 28 September, when the first heavy night frost killed the tops; yielded an average of 3 bushels of marketable and two of undersized potatoes per bed.

The authors point out that with earlier sowing in the first week of June, when the danger of heavy frost is virtually over, more than three months of reasonably good growing weather would be available, sufficient to bring to maturity all the crops employed in the experiment.

The importance of these experiments, incomplete though they are, is considerable, and repetition, with earlier sowing, would well repay the investigators. The results, moreover, provide a basis on which, with a minimum of equipment, small-scale experiments in vegetable cultivation could be carried out at isolated stations in the Arctic and Antarctic. As Hill and Gilbey point out in their concluding remarks: "although installation costs are high, production is economically sound when the cost and percentage spoilage of imported produce is considered. It is possible that in other areas of unproductive soil, sufficient produce could be raised to prevent nutritional diseases in communities engaged in the exploitation of mineral and other natural resources."

S. MAX WALTERS

\title{
HARDNESS OF ICE AT LOW TEMPERATURES
}

[Summarised from an article by Eliot Blackwelder in the American Journal of Science, Vol. 238, No. 1, 1940, pp. 61-62.]

It has long been known that ice is subject to great varieties of hardness according to temperature. According to observations recorded by Carl Teichert in 1939, the hardness of ice increases from about 2 (on the Mohrs scale) or less at temperatures near freezing-point, to 4 at a temperature of $-44^{\circ} \mathrm{C}$., and should be about 6 at $-50^{\circ} \mathrm{C}$. As this report seemed to rest only on field observations made by Albrecht Heim in the Alps and later by Alfred Wegener in Greenland, it was desirable to have confirmation. Dr E. Blackwelder therefore arranged for Mr Ira Klein to make careful scratching tests in a 
mineralogy laboratory, cooling cubes of ice down to the temperature of solid carbon dioxide. At this temperature of $-78 \cdot 5^{\circ} \mathrm{C}$. the hardness of ice was found to be approximately 6 , or that of orthoclase felspar.

Apart from its significance to students of mineralogy, physics and geomorphology, the fact that ice increases in hardness inversely with temperature is of considerable interest to polar travellers. Air temperatures in polar regions often fall below $-50^{\circ} \mathrm{C}$., and temperatures of $-70^{\circ} \mathrm{C}$. are by no means unknown in the coldest parts of the globe. Ice with a hardness of 5 or even 6 should therefore not be uncommon.

These investigations now provide an explanation of the all too familiar stinging sensation of ice crystals striking against the face during blizzards, of the remarkable shapes into which hard snowdrifts are carved at such times, and of the excessive wear on sledge runners at very low temperatures.

\section{GEOGRAPHIC INCIDENCE OF AURORA AND MAGNETIC DISTURBANCE IN THE NORTHERN AND SOUTHERN HEMISPHERES}

[Review of papers by E. H. Vestine in Terrestrial Magnetism and Atmospheric Electricity, Vol. 49, No. 2, June 1944, pp. 77-102, and by E. H. Vestine and E. J. Snyder, loc. cit., Vol. 50, No. 2, June 1945, pp. 105-24.]

In the first of these papers the author has extended the well-known memoir published by Fritz in 1881, in which the frequency and characteristics of aurora observed in the Northern Hemisphere during the years 1700-1872 were discussed. Mr Vestine has now constructed a map of isochasms of equal auroral frequency, by using material collected by the International Polar Year expeditions of 1882-83 and 1932-33 and by other expeditions. On his map Fritz did not attempt to draw isochasms inside the zone of maximum auroral frequency; but using statistical methods and making allowances for the influence of cloudiness and daylight, Vestine has attempted to draw isochasms in the region of the geomagnetic pole. The isochasms of auroral frequency are compared with curves of equal geomagnetic disturbance compiled from information obtained during the 1932-33 Polar Year. The curves are similar to the auroral isochasms and the zone of maximum geomagnetic disturbance coincides with the auroral maximum zone.

Owing to comparative scarcity of observations the same methods cannot be used for deriving similar charts for the Southern Hemisphere, and in the second paper the authors have compared the average features of geomagnetic disturbance and aurora in southern latitudes with those derived from more extensive data for northern latitudes. The seasonal and yearly average of the disturbance daily variation is obtained for various stations in Antarctic regions, and its variation in amplitude with latitude is compared with that for the Northern Hemisphere. These data are used to estimate the position of the southern zone of maximum auroral frequency. 